\title{
AMBIENTE E CULTURA KAINGANG: SAÚDE E EDUCAC̣ÃO NA PAUTA DAS LUTAS E CONQUISTAS DOS KAINGANG DE UMA TERRA INDÍGENA
}

Luís Fernando da Silva Laroque* Juciane Beatriz Sehn da Silva**

\begin{abstract}
RESUMO: Este artigo tem por objetivo discutir questões relacionadas à saúde e educação indígena Kaingang da Terra Indígena Linha Glória, localizada no município de Estrela, no Vale do Taquari-RS. Os Kaingang são povos de língua Jê, constituindo, na atualidade, um dos maiores grupos do ponto de vista populacional no Sul do Brasil, ocupando territórios localizados no oeste paulista, centro-norte e oeste paranaenses, oeste catarinense e centro-norte do Rio Grande do Sul. Sendo assim, buscamos compreender como esse grupo vivencia e relaciona-se culturalmente com a saúde e a educação no seu cotidiano. Pretendemos, sobretudo, mostrar que o grupo tem sido sujeito de sua história, estando à frente de diversas lutas relacionadas à saúde e educação, e que a Constituição Federal de 1988 garante, nos termos específicos da lei, que ambas sejam realizadas de maneira diferenciada, respeitando a cultura e a peculiaridade das populações indígenas.
\end{abstract}

Palavras-chave: Kaingang; Terra Indígena Linha Glória; Saúde e Educação; Vale do Taquari.

\section{KAINGANG ENVIRONMENT AND CULTURE: HEALTH AND EDUCATION IN THE AGENDA OF STRUGGLES AND ACHIEVEMENTS OF AN INDIGENOUS LAND}

ABSTRACT: In this paper, we aimed to discuss questions related to Kaingang health and education in the Indigenous Land 'Linha Glória' located in the municipality of Estrela, Taquari valley. The Kaingang speak the so called 'Jê' language. Nowadays, they are one of the most populous indigenous groups in southern Brazil, occupying territories situated in western São Paulo, center-north and western Paraná, western Santa Catarina and center-north Rio Grande do Sul states. Thus, we sought to comprehend the ways these populations experience and relate culturally with health and education in their everyday lives. We intend, especially, to show that this indigenous group has been an active player of its own history, being ahead of several struggles related to health and education, and that the Federal Constitution of 1988 guarantees, in the specific terms of law, that both are conducted differently, respecting the culture and uniqueness of indigenous populations.

Keywords: Kaingang; Indigenous Land 'Linha Glória'; Health and Education; Taquari Valley.

\footnotetext{
* Doutor em História pela Universidade do Vale do Rio dos Sinos (UNISINOS) e do Programa de Pós-Graduação em Ambiente e Desenvolvimento do Centro Universitário - Unidade Integrada Vale do Taquaril de Ensino Superior (UNIVATES). E-mail: Iflaroque@terra.com.br

** Licenciada em História pelo Centro Universitário - Unidade Integrada Vale do Taquaril de Ensino Superior (UNIVATES) e Professora da Educação Básica. E-mail: sehn@universo.univates.br
} 


\section{INTRODUCุÃO}

O espaço Kaingang é uma construção cultural. Há uma amálgama entre os mundos natural, simbólico e social, dos quais a vida Kaingang não está dissociada, e sua reprodução física e social depende da inter-relação e do equilíbrio que se estabelecem entre eles. Com efeito, sua concepção de mundo influencia e é influenciada pela maneira como o ecossistema é percebido.

A forma como os indígenas interagem com seu ambiente oferece informações riquíssimas sobre as inter-relações ecológicas e culturais desses grupos. Nesse sentido, Darrell Posey (1986) enfatiza que é importantíssimo preservar as sociedades indígenas e seus saberes, pois elas constituem um patrimônio humano inestimável da cultura universal.

Os Kaingang produzem seus territórios de acordo com uma concepção própria de tempo e espaço. O modo de vida Kaingang implica uma relação específica com a natureza e entre si, de acordo com representações simbólicas historicamente elaboradas, que conferem sentido às suas práticas materiais e sociais em que, consequentemente, saúde e educação estão inseridas. Ser e tornar-se humano está relacionado com o viver, de acordo com o modelo prático e simbólico Kaingang.

Segundo Fredrik Barth (2000), a cultura é a linguagem da diferença. Nessa perspectiva, a cultura mantém um caráter comunicativo e interpretativo, enquanto que a linguagem demarca a diferença. A cultura, para além de ser um conceito ainda importante no campo antropológico, no diálogo intercultural que marca a disciplina, tornou-se um termo nativo, apropriado pelos indígenas para referirem-se às suas tradições e demarcarem sua diferença (MORAES, 2009).

$\mathrm{Na}$ realização deste estudo, nos baseamos em fontes bibliográficas (ensaios, artigos e dissertações de mestrado e doutorado) e em fontes documentais (laudos antropológicos, legislações, pareceres, ofícios e procedimentos administrativos). Além disso, nos utilizamos da metodologia de história oral durante a pesquisa de campo, tanto na Terra Indígena Linha Glória, em Estrela, como no contato com os atores e agências oficiais ou não ligadas à pesquisa. Como base teórico-metodológica para a análise dos dados estudados, nos respaldamos em estudos como o de Barth (2000), Mussi (2000), Brand (2000), Luciano (2006), Matte (2009) e Bergamaschi e Dias (2009). 


\section{SAÚDE INDÍGENA KAINGANG NUM CONTEXTO AMBIENTAL E XAMÂNICO}

Falar de saúde indígena é, sobretudo, falar do ambiente como um todo, onde a terra é o elemento primordial, entendido pelos Kaingang como a mãe de todos os elementos da natureza e de si mesmo, pois, enquanto espécie/ser, também é parte constitutiva desse universo natural, estando intimamente ligado a ele. Para o Kaingang, a terra o fez nascer, isso porque, conforme seu mito de origem, os primeiros Kaingang saíram da terra.

Considerando o mito de origem Kaingang, é possível perceber que, na concepção desse grupo, seus ancestrais saíram da terra. Essa é uma explicação mítico-cosmológica, que serve não só para compreender o surgimento desse grupo, mas de outros elementos da natureza que são criados a partir deles. Os Kaingang acreditam também que, assim como saíram da terra, a ela retornarão depois de mortos. Dessa forma, não se colocam acima de outras espécies e/ou seres do universo, ou seja, estão interligados num mesmo nível de relações. São dimensões que estão em contínua comunicação. Essa é uma questão cultural riquíssima dos Kaingang. Nessa perspectiva, o depoente H destaca:

\footnotetext{
Na questão da saúde, os Kaingang têm uma visão interligada entre os diversos seres e elementos do universo! Não é linear ou fracionada, separando, por exemplo, o ritmo ou tempo como a sociedade nacional; a pessoa, da árvore ou dos animais; ou, ainda, localizando e tratando a doença somente a partir de uma parte do corpo, num espaço físico ou numa secretaria. O bem-estar, a saúde e a alegria estão presentes, quando os seres do universo estão bem. O bem-estar, a alegria e a saúde dos Kaingang está ligada, diretamente, com a saúde e a vida das abelhas, dos pássaros e da importante diversidade do capim. Estes seres estão todos interligados. (ENTREVISTA H, 2011, p. 2).
}

A ligação com a natureza perpassa e está presente na saúde dos indígenas Kaingang. Há um ciclo natural, em que a existência de cada ser é imprescindível para o equilíbrio da vida. O Kaingang informa que está doente devido à destruição de suas florestas, pois não há como ter saúde sem que todos os elementos estejam em equilíbrio. Segundo ele, as águas estão poluídas, as matas nativas desapareceram, em sua grande maioria, cortadas; muitos animais vivem em áreas de proteção, pois, no período atual, já não podem viver livremente, e tantos outros exemplos de alteração dos ecossistemas. 
O indígena Kaingang percebe essas questões porque compreende que a natureza é primordial para sua própria existência e por isso a valoriza tanto. Em outras palavras, os Kaingang têm uma visão global, da qual o ser humano não está, de forma alguma, dissociado do ambiente. A conservação da mata virgem, por sua vez, também é fundamental na cosmologia tradicional dessa sociedade. Por um lado, por meio dela, se perpetua o sistema xamânico: é fonte de material vegetal necessário às atividades rituais e curativas do Kuiā e é o espaço para onde se remetem os espíritos dos mortos. Portanto, a existência fundamental da complementaridade entre a casa, o limpo e o mato virgem dá-se à base da cosmologia Kaingang, e a quebra dessa ordem pode gerar desequilíbrios emocionais e sociais (ALMEIDA; WIIK; FERNANDES, 2009). Assim, o Kuiã atua em processos de cura com plantas do mato virgem e de orientação das famílias com visitas nas residências.

A pequena área de vegetação que existe atualmente no entorno da Terra Indígena Linha Glória tem muita importância para o grupo. É dela que retiram remédios, matéria-prima para a confecção de artesanatos e usufruem das frutas, conforme relato da líder Maria Antonia Soares.

A gente tem conhecimento de bastante remédio também; pra índio, assim né? O que pra vocês, às vezes, sei lá, parece só mato, pra gente é tudo isso... É pequeno aquele mato, mas tem tudo, taquara, cipó, árvores, remédios. Ali tem muito remédio. (GONÇALVES, 2008, p. 31).

Essa vegetação apresenta espécies nativas e exóticas, imprescindíveis para esse grupo indígena. No trecho dessa pequena mata, há um arroio que cruza a porção sul do acampamento, separando-o da escola.

O grupo da Terra Indígena Linha Glória é formado por cerca de 150 Kaingang, que ocupam um espaço limitado de apenas 14 hectares de terra, que se encontra em situação irregular, ou seja, não é reconhecida como Terra Indígena pela Fundação Nacional do Índio (Funai). Parte das terras é de domínio do Departamento Autônomo de Estradas de Rodagem (DAER) e outra parte é de propriedade particular. Por tradição, as famílias possuem, em média, quatro ou cinco filhos. A tradição medicinal do uso das plantas é amplamente utilizada pelo grupo, sendo que as Kaingang mais velhas têm a função primordial de ensinar as gerações mais novas sobre o valor medicinal das plantas. 
Em entrevista com uma das indígenas anciãs do grupo, a depoente demonstrou que tem pleno conhecimento das plantas que há na pequena área de vegetação da Terra Indígena Linha Glória, bem como as utiliza amplamente no seu cotidiano. Quando questionada sobre o que fazem quando alguém está doente, ela responde:

Usa planta do mato! Tem muito chá do mato que é bãom! Tem a cancorosa, o chá de boldo também é bãom! Aquele outro, a quina, que também é bãom! O ipê roxo! O ipê roxo é bãom pra toda coisa! A quina é bãom pro estômago. Se a senhora tá bem doente faz um chá de quina e toma, fica bãom, sarô! É que nem esses dia que eu tava ruim, tomei um chá de quina, foi pra já que eu sarei de novo! Eu sou assim, eu posso tá nas úrtimas, mas eu não gosto de médico! Eu não percuro médico! Primeiro o chá do mato! [...] A folha de laranja também é bãom! Capim-cidreira também é bãom! Esse poejo, como é que se diz, é bãom pra criança. A florzinha do maracujá... Esse maracujá é bãom pra bronquite! A flor é bãom! A casca da laranja também é remédio, também é bãom! (ENTREVISTA D, 2011, p. 2).

Além desse conhecimento das plantas medicinais, verifica-se também que, durante largo período de tempo, as mulheres Kaingang tiveram seus filhos na Terra Indígena Linha Glória, realizando o parto muitas vezes sozinhas ou com ajuda de uma parteira, que era sempre uma indígena mais velha. Durante o nascimento, realizam a prática do corte do umbigo e, a partir daí, segue-se todo um ritual repleto de significado cosmológico, que culmina com o enterramento desse umbigo na área da aldeia. Vejamos o que nos diz uma depoente sobre a prática dos nascimentos:

Dois eu ganhei aqui embaixo do arvoredo. Eu cortei o umbigo! E um eu ganhei lá na colônia quando eu fui passear na casa da minha mãe né! Naquele tempo eu tinha a mãe, ela era viva, e daí eu fui passeá lá e daí eu não me esqueci muito bem aquele dia, daí eu saí pra vim embora pra casa e eu ganhei, e no outro dia eu voltei pra casa (ENTREVISTA E, 2011, p. 2).

Há aspectos muito peculiares da cerimônia ritualística do corte do umbigo.

O pai dava banho nas crianças, né mãe? Quando nascia um nenenzinho, ele mandava dar banho na sanga e daí ele passava no fogo [utilizando ervas do mato]. Meu umbigo foi cortado com taquara, né mãe? [...] Eram os kujá quem faziam os partos da gente, os benzedor, que eles chamavam, os curandor [diz 
Lídia: parteiras]. Meu pai dizia: seu umbigo foi cortado com taquara. Peguei uma taquara lá no mato e daí teu avô e tua avó cortaram teu umbigo, a mãe velha, que eles diziam [...] a velha que cortou. (GONÇALVES, 2008, p. 74, grifo do autor).

Sobre essa prática do uso da taquara para cortar o cordão umbilical e do uso da água para o banho do recém-nascido, Ítala Basile Becker (1995) refere que já usavam essa planta no passado. A taquara é uma planta de referência na vida do Kaingang e está ligada, dentre tantas outras utilidades², também à medicina, "[...] servindo uma tala de taquara para cortar o cordão umbilical ao recém-nascido, operação que completam com uma atadura feita com cordel de embira ou tucum.” (BECKER, 1995, p. 176). Segundo podemos constatar, Manoel Soares, patriarca da aldeia, manteve essa prática cultural dos seus antepassados com seus filhos. Nesse sentido, é interessante a constatação de Antônio Brand (2000) sobre as culturas orais, na medida em que destaca que o ato de lembrar é reviver, refazendo, reconstruindo, repensando a partir do impacto da realidade.

Atualmente, as mulheres recebem acompanhamento de uma agente de saúde indígena da própria comunidade da Terra Indígena Linha Glória. O direito de ter um profissional indígena mediando questões de saúde foi uma grande conquista do grupo. Essa evidência fica clara na fala do depoente B, ao ser questionado sobre a forma como o Ministério Público Federal tem intermediado as questões de saúde junto ao grupo da Terra Indígena Linha Glória, que informa o seguinte:

Uma delas é a contratação da agente de saúde indígena. Isso foi muito negociado com o município de Estrela e se conseguiu. [...] Nós entendemos que é uma conquista ter um agente de saúde indígena, por mais que se questione, "Ah, tem um agente que serve aquele bairro?”, por exemplo, um agente de saúde indígena para os brancos, normal do SUS. Então nós vemos que não é só uma questão de ter uma agente de saúde indígena para o bairro, a questão é a peculiaridade indígena. (ENTREVISTA B, 2011, p. 3).

É por meio da agente de saúde indígena que os Kaingang recebem acompanhamento do posto de saúde do município de Estrela. Quando há a necessidade de realizar algum tratamento que não possa ser resolvido com o uso de sua medicina tradicional, os indígenas utilizam o posto de saúde do bairro Imigrante, em Estrela. Conforme referido anteriormente por 
um de nossos depoentes, apenas em casos de extração de dentes, exames pré-câncer, dores na coluna, por exemplo, que procuram auxílio médico. $\mathrm{O}$ acompanhamento das gestantes também é realizado pela agente de saúde indígena. Sobre essa situação, o depoente B destaca:

Muitas vezes há questões que nem se imagina, porque a questão da gravidez das indígenas, isso tem toda uma peculiaridade própria que só... Eu imaginava assim essa questão: pra mulher branca já é difícil ter um contato com um enfermeiro, com um agente de saúde branco, imagina para uma indígena, como é mais difícil ainda! Nós insistimos nisso e conseguimos [Refere-se à contratação do agente indígena]. (ENTREVISTA B, 2011, p. 3).

A participação do grupo no Conselho Estadual dos Povos Indígenas (CEPI), iniciada em 2002, mediante a liderança de Maria Antonia Soares, foi muito importante, pois, a partir de então, o grupo passou a receber maior apoio da Fundação Nacional do Índio (Funai) e da Fundação Nacional da Saúde (Funasa). A Funasa, até pouco tempo atrás, era o órgão federal responsável pela gestão da saúde pública no Brasil. No entanto, as demandas junto a esse órgão eram sempre várias e as respostas muitas vezes levavam meses e até anos para serem efetivadas, ou simplesmente não aconteciam. Em 19 de outubro de 2010, o então presidente da República criou a Secretaria Especial de Saúde Indígena (Sesai). O novo órgão passou a ser subordinado ao Ministério da Saúde, que passa a gerenciar diretamente serviços relacionados à saúde indígena e projetos de saneamento básico nas aldeias, áreas antes coordenadas pela Funasa.

A Terra Indígena Linha Glória apresenta um grave problema que acompanha o grupo desde sua efetiva instalação no local, que é a falta de saneamento básico. Diante das reivindicações da comunidade junto à Fundação Nacional da Saúde, o órgão competente argumenta que não pode realizar melhorias, pois a área não possui título de Terra Indígena.

A Funasa prioriza a execução de ações de saneamento para terras homologadas - terras demarcadas e com Decreto de Homologação do Presidente da República, registradas - terras inscritas nos Cartórios de Registros de Imóveis da Comarca e no Departamento de Patrimônio da União (conforme Art. $6^{\circ}$ do Decreto $\left.\mathrm{n}^{\circ} 1.775 / 96\right)$. Os investimentos permanentes são realizados nestes termos ou em terras cujos processos de homologação apresentem, pelo menos, Declaração - terra com Portaria Declaratória do Ministério da Justiça ou Interministerial, além das Portarias da Funai, quando for o caso. (FUNDAÇÃO NACIONAL DA SAÚDE, 2007, p. 1, grifo do autor). 
Essa questão é antiga e recorrente na pauta de reivindicações e problemas urgentes da aldeia ligados à saúde. Hoje a Terra Indígena dispõe de apenas um único sanitário, localizado na escola, e duas patentes na área da aldeia em situação precária. Sobre a questão sanitária, o depoente B enfatiza:

[...] também o que nos preocupa há muito tempo é a questão sanitária. A questão dos banheiros. Nós tínhamos insistido desde 2007 com esta questão dos banheiros com a Funasa, mas aí agora o que se desenha e o que nós vamos insistir muito junto ao DNIT e junto a Funai é que com a nova área que vão garantir que construir casas, vão transportar aquelas casas, vamos insistir para que eles não se oponham a construção de banheiros [...] (ENTREVISTA B, 2011, p. 2).

A água disponível na Terra Indígena é proveniente de um reservatório e é bombeada de um poço artesiano, construído no ano de 2002. Essa água está canalizada em um único ponto da aldeia, sendo que, para o uso diário, as cerca de 30 famílias necessitam se deslocar para essa torneira central, visando suprir suas necessidades básicas. Na escola, há também uma torneira ligada a esse reservatório de água, que é utilizada por algumas famílias que residem nas proximidades. Para o banho diário, o grupo utiliza um córrego que existe próximo à Terra Indígena, uma vez que não há um lugar para o banho.

\section{ESCOLA ESTADUAL INDÍGENA DE ENSINO FUNDAMENTAL MANOEL SOARES: ESPACְO DE VALORIZACฺÃO DA IDENTIDADE ÉTNICA}

Com a promulgação da Constituição de 1988 (BRASIL, 1988), assegurou-se aos povos indígenas o direito a uma educação escolar diferenciada, com processos próprios de aprendizagem e utilização de suas línguas maternas. Dessa forma, as escolas indígenas deveriam transformar-se num espaço de preservação de suas organizações sociais, dos costumes, das línguas e crenças e também do aprendizado da cultura e dos valores comuns ao povo brasileiro. Nessa linha de raciocínio, temos:

Assim, a educação indígena refere-se aos processos próprios de transmissão e produção dos conhecimentos dos povos indígenas, enquanto a educação escolar indígena diz respeito aos processos de transmissão e produção dos conhecimentos não indígenas e indígenas por meio da escola, que é uma instituição própria dos povos colonizadores. (LUCIANO, 2006, p. 129). 
O Decreto Federal n. 26, de 4 de fevereiro de 1991, estabelece as competências quanto à educação escolar indígena, ficando atribuída ao Ministério da Educação a coordenação das ações referentes à educação indígena, e às secretarias de Educação dos estados e municípios o desenvolvimento de ações em todos os níveis e modalidades de ensino (CONSELHO ESTADUAL DE EDUCAÇÃO DO RIO GRANDE DO SUL, 2002). A Lei de Diretrizes e Bases da Educação Nacional (LDBEN), Lei n. 9.394, de 1996 (BRASIL, 1996, p. 27), estabelece normas específicas para a educação indígena e assevera legalmente o uso das línguas maternas nas escolas indígenas, proporcionando "[...] a recuperação de suas memórias históricas, a reafirmação de suas identidades étnicas, a valorização de suas línguas e ciência.” A Lei n. 10.172, de 2001 (BRASIL, 2001), estabelece o Plano Nacional de Educação, em que a educação indígena é devidamente contemplada. O Decreto n. 5.051, de 2004 (BRASIL, 2004), promulga a Convenção da Organização Internacional do Trabalho (OIT), assegurando aos indígenas direitos específicos à educação. Outros documentos oficiais decorrentes dessa legislação fundamental atribuem à educação indígena o caráter de diferenciada, específica, intercultural e bilíngue (MAT'TE, 2009).

Com o reconhecimento da Terra Indígena Kaingang Linha Glória pela Funai, em 2002, o governo do estado do Rio Grande do Sul, por meio da Secretaria de Educação, foi responsável pela gestão da construção da escola indígena às margens da BR-386 e sua posterior autorização de funcionamento. Por meio do decreto n. 41.700, de 3 de julho de 2002 (RIO GRANDE DO SUL, 2002), o então governador criou e denominou o referido estabelecimento de ensino como Escola Indígena Manoel Soares. Mesmo não tendo o credenciamento e a autorização de funcionamento e "centro de custos", a escola iniciou suas atividades a partir de sua criação.

A Escola Indígena Manoel Soares foi construída mediante parcerias com organizações não governamentais (ONGs) e entidades filantrópicas, e subsidiada pela 3. ${ }^{a}$ Coordenadoria Regional de Educação (CRE), que doou os materiais rústicos (restos de um galpão de madeira de uma escola de Estrela). Essa construção inicial possuía somente quatro paredes, duas janelas e uma porta. Não havia sanitários nem cozinha. A merenda escolar era enviada pelo Conselho Tutelar, que a conseguia por meio de ações judiciais de doação de cestas básicas (LAJEADO, 2004c). 
A construção aconteceu em janeiro de 2002, visando suprir a necessidade de oferecer uma educação voltada à peculiaridade indígena, já que as crianças não tinham acesso, na escola regular que frequentavam, a um aprendizado voltado à sua cultura indígena e na sua língua materna. Fica evidente, na fala do depoente A, a exclusão a que era submetido o grupo indígena da Terra Indígena Linha Glória pelos não indígenas e a necessidade da implantação dessa escola dentro da aldeia:

[...] Este trabalho era para que este grupo excluído tivesse pelo menos acesso a uma boa educação na cultura deles. Boa educação eles tinham lá na escola Pedro Braun. Nós queríamos que esse grupo tivesse uma boa educação na cultura deles, onde eles iam. Mas na cultura deles não se adaptava, era um choque de culturas que tinha. Os professores da escola Pedro Braun eram muito bons. Pra assumir e pra trabalhar toda esta questão eu achei que eles foram muito competentes. Então em janeiro nós chamamos a Juraci Padilha e nós fomos ver como construir a escola lá! [...] (ENTREVISTA A, 2011, p. 4).

Tal situação pode ser verificada também em documento oficial do Ministério Público Federal que, ao solicitar a autorização oficial da escola e o "centro de custos", refere que "[...] as crianças indígenas não querem estudar na escola estadual regular mais próxima - pois já foram submetidas a situações de preconceito e discriminação.” (LAJEADO, 2004b, p. 1).

Nesse período inicial de implantação da escola, muitos desafios e dificuldades surgiram. Inicialmente, foi preciso que se contratasse um professor para trabalhar na escola. Sobre os primeiros professores temos o seguinte:

[...] A primeira professora foi a indígena, a Juraci Padilha - teóloga - e ela não conseguiu ser admitida como professora porque ela tinha um contrato, aliás nomeação de merendeira. Ela é hoje merendeira lá na escola Vinte de Maio [Estrela]. Ela iniciou esta escola com muito sofrimento. A escola estava lá e se não iam na aula, ela ia buscar e fazer todo um trabalho para que eles começassem a vir para a escola. Depois dela, foi nomeado um professor, ele era Matte [Carlos Matte]. Depois dele, veio esse casal, o Magnus e a Tamar [...] (ENTREVISTA A, 2011, p. 6).

A escola já estava em funcionamento desde seu ato de criação, há cerca de dois anos, quando então foi regularizada junto ao Conselho Estadual de Educação do Rio Grande do Sul, pelo Parecer no 447/2004, em 7 de julho 
de 2004, como Escola Estadual Indígena de Ensino Fundamental Manoel Soares - Escola de Ensino Fundamental de $1 .^{\circ}$ ao 5. Ano (ESTRELA, 2004). Com as reivindicações realizadas pelo professor Carlos Matte à 3. ${ }^{a}$ Coordenadoria Regional de Educação (CRE), em 2003, houve mobilizações para a realização de melhorias na escola, resultando na construção de um sanitário feminino com vaso e uma pia, um sanitário masculino com um vaso, uma pia e um box com chuveiro. À frente da área construída, foi adaptada uma pequena cozinha para ser utilizada no preparo da merenda escolar.

Com base em documentação específica do Ministério Público Federal, verifica-se que, logo após a autorização de funcionamento da escola pelo Conselho Estadual de Educação, em 2004, a Procuradoria da República mobiliza uma ação questionando sobre a situação da escola. No parecer, elaborado pelo Conselho, consta como sendo "suficiente e adequada", o que não condiz, segundo a Procuradoria, com a realidade, estando portanto longe de atender aos parâmetros de funcionamento dispostos no Parecer $\mathrm{n}^{\circ}$ 383/2002 (LAJEADO, 2004a). O que se percebe, porém, é que, de 2004 até 2011, essa realidade praticamente não mudou. Tendo em vista que parte do local é de domínio do Departamento Autônomo de Estradas de Rodagem (DAER) e que a comunidade indígena não possui ainda o título de Terra Indígena, a Secretaria de Educação diz não poder investir verbas oficiais por força de lei onde a terra não está legalizada.

Há muitos anseios do grupo com relação à escola, especialmente no que se refere ao direito de ter professores indígenas trabalhando na educação das crianças Kaingang e de ter um professor bilíngue, para o ensino da/na língua materna, o que é fundamental para a revitalização, valorização e o fortalecimento da cultura Kaingang. Alguns Kaingang da Terra Indígena Linha Glória acabaram perdendo a língua materna com o passar dos anos. Isso se deve ao fato de que Manoel Soares, patriarca da aldeia, num dado momento, não pôde mais praticá-la, pois os fazendeiros que lhe ofereciam trabalho na lavoura não permitiam essa prática, como eles dizem: "os brancos achavam que os índios falavam mal deles” (GONÇALVES, 2008, p. 64). Sabemos também que, em meados da década de 1960, assumir-se indígena fora dos espaços delimitados pelo governo como "reservas indígenas" e manter a língua materna eram motivos de perseguição pelos órgãos do governo. O grupo da Terra Indígena Linha Glória manifesta o desejo de revitalizá-la e fazer com que seus filhos possam aprendê-la. 
O Parecer $n^{\circ}$ 383/2002 (CONSELHO ESTADUAL DE EDUCAÇÃO DO RIO GRANDE DO SUL, 2002, p. 4), que estabelece normas para o funcionamento de escolas indígenas no Sistema Estadual de Ensino do Rio Grande do Sul, já referido anteriormente, dispõe, no item "Profissionais da Escola Indígena", que o professor deve, "preferencialmente, ser membro da comunidade". Segundo esse parecer, o êxito das escolas indígenas seria muito maior se os profissionais que nela atuam na função de docentes e nas de apoio fossem membros da mesma comunidade indígena.

É importante refletirmos que a concepção de escola para o grupo indígena Kaingang é diferente da concepção que nós, não indígenas, temos. Bartomeu Melià apresenta com propriedade o contrassenso se tomarmos como parâmetro a concepção de escola e educação da sociedade não indígena para analisarmos as indígenas.

Muitos dos que tentaram fazer a educação para o índio constatam com amargor
e desespero que "o índio não muda". O índio perpetua o seu modo de ser,
nos seus costumes, na sua visão de mundo, nas relações com os outros, na sua
religião. E isso com tal firmeza e força que desafia as explicações simplistas. Uma
dessas é que o índio é "índio mesmo por natureza"; como o bicho do mato. É
fácil de ver que essas explicações fisiológico-raciais, além de conterem ideologias
racistas, carecem de qualquer fundamento científico (MELIÀ, 1979, p. 9).

Sobre essa questão, que é de fundamental importância para entendermos qual o papel que a escola indígena exerce dentro dessa comunidade e o que os indígenas esperam efetivamente dela, pode ser analisado a partir da experiência do depoente $\mathrm{H}$ :

Então a escola hoje ela é importante no momento em que ela de fato cumprir o seu papel de ser uma escola bilíngue, que ainda estamos longe, longe, longe disso. Mas ainda assim ela é importante no sentido da revitalização dessas culturas, de que as crianças percebam, é importante que nem no caso da Linha Glória de retomar a sua língua! Os valores dessa cultura podem ser aprofundados pela escola. [...] A escola pode ajudar na questão de compreender também a sociedade nacional, porque eles são muitas vezes, digamos assim, invadidos por concepções, valores e obrigações que vêm da sociedade nacional e que não fazem parte dos valores deles e eles não sabem como lidar às vezes (ENTREVISTA H, 2011, p. 2-3).

Em resumo, o que os Kaingang esperam da escola é que ela possa, acima de tudo, respeitar o jeito de ser indígena e também ajudar a compreender 
a sociedade nacional, visando fortalecer cada vez mais sua própria cultura. O professor indígena Dorvalino, que trabalha na Terra Indígena Kaingang Por Fi Gâ, em São Leopoldo, refere-se à língua Kaingang como "língua sagrada", pois a memória, a lógica e toda a estrutura do pensamento é construída a partir dessa língua. Então, cada palavra Kaingang está repleta de significados que, muitas vezes, não são compreendidos senão por aqueles que vivem nessa cultura. Daí a importância do professor bilíngue e do ensino e revitalização da língua materna para a Terra Indígena Linha Glória.

Dessa forma, a escola indígena deveria constituir-se um canal de diálogo com o mundo não indígena, possibilitando o acesso a conhecimentos que tornam a sociedade não indígena mais compreensível, como a escrita, a leitura, o sistema monetário e a língua portuguesa. Também é uma "ferramenta de luta", sem abrir mão dos saberes tradicionais que são a base da educação das aldeias, garantindo assim um relacionamento mais equilibrado entre as diferentes culturas indígenas e não indígenas (BERGAMASCHI; DIAS, 2009).

O professor Dorvalino Cardoso, que hoje trabalha na aldeia Por Fi Gâ, em São Leopoldo, chegou também a atuar na escola Terra Indígena Linha Glória nos anos de 2005 e 2006. Na época, ele veio com sua família da Terra Indígena Votouro, que se localiza em Benjamin Constant, e permaneceu como professor da língua Kaingang até maio de 2006, quando então foi para São Leopoldo. Antes dele, a escola teve outro professor que veio da Terra Indígena Iraí, referido como Sandro Topẽ da Silva. Ele atuou de agosto de 2004 até fevereiro de 2005, quando retornou para Iraí. Somente em 2008 é que a escola teve novamente um professor para trabalhar a língua Kaingang, o indígena João Maria Fortes, da Terra Indígena Planalto, município de Pinhalzinho-SC, que ficou na escola por apenas dois meses, no período de maio a junho de 2008. Como ele não se adaptou, decidiu voltar para a sua aldeia de origem. Desde então, a escola não teve outro professor bilíngue (ENTREVISTA D, 2011, p. 1).

No ano de 2011, frequentavam a Escola Estadual Indígena Manoel Soares 27 crianças Kaingang, que estavam matriculadas de acordo com seus respectivos anos de ensino, o que abrange de $1 .^{\circ}$ ao $5 .^{\circ}$ ano do ensino fundamental. As turmas estavam assim constituídas: $1 .^{\circ}$ ano -4 alunos; 2. ${ }^{\circ}$ ano -6 alunos; $3 .^{\circ}$ ano -8 alunos; $4 .^{\circ}$ ano -4 alunos; $5 .^{\circ}$ ano -5 alunos (ESCOLA ESTADUAL INDÍGENA DE ENSINO FUNDAMENTAL MANOEL SOARES, 2011). As crianças estudam todas juntas em uma 
única sala, em regime de classe multisseriada, e são atendidas por uma única professora alfabetizadora. Além da professora alfabetizadora, a escola possui ainda o/a diretor(a) e uma funcionária, esta responsável pela limpeza e pela elaboração da merenda.

A fase que corresponde à primeira infância ${ }^{3}$ é marcada pelo aprendizado social. As crianças crescem e se tornam adultas, brincando, imitando os pais, ouvindo histórias que os mais velhos contam, participando das atividades cotidianas e de rituais do grupo. Brincam nas árvores, penduram-se em cipós, andam de bicicleta e jogam futebol, totalmente integradas ao meio ambiente que lhes é familiar. A atitude dos pais e dos mais velhos é sempre de grande tolerância, paciência, atenção e respeito às suas peculiaridades. Desde cedo, as crianças aprendem as regras do jogo social, mesmo os pais sendo os responsáveis mais diretos pela criação dos filhos. As crianças são integradas na vida comunitária, aprendendo o que pode e o que não pode ser feito (GONÇALVES, 2011).

As crianças ingressam na escola aos seis anos de idade e lá permanecem até completarem o $5 .^{\circ}$ ano do ensino fundamental. Concluídos os estudos na escola indígena, os alunos são então encaminhados para a Escola Estadual de Ensino Fundamental Pedro Braun, que se localiza na Vila Glória, em Estrela. Em 2011, quinze crianças frequentaram a escola Pedro Braun. Após completarem o 9. ano, vão para uma escola de ensino médio, também em Estrela. Porém, o que constatamos é que são poucos os indígenas que, na atualidade, dão continuidade aos estudos após completarem o ensino fundamental, devido a muitas questões que perpassam essencialmente pelo respeito à diversidade cultural. Muitas vezes os indígenas são desestimulados a continuarem seus estudos pela falta de apoio dos órgãos públicos competentes e, mesmo, dos educandários, que, na prática, dizem não estarem preparados para acolher alunos indígenas, bem como não contemplam, em sua Proposta Político-Pedagógica, a questão indígena. Há um longo caminho a percorrer no sentido de acolhida das populações indígenas pela sociedade não índia nos espaços destinados à educação, vinculada a uma instituição tradicional.

Nesse sentido, temos:

Um dos pressupostos básicos para essa discussão é o entendimento e a afirmação de que sempre houve formas próprias de educação indígena e que as suas pedagogias são valores fundamentais que devem também orientar os 
trabalhos escolares. Entendemos educação como todo o conhecimento que uma comunidade ou povo possui e que é de domínio de todos, transmitido de pais para filhos e necessário para se viver bem. Neste sentido, educação não é o mesmo que escola. É o processo através do qual toda pessoa aprende a viver. Essa aprendizagem se dá na família, na comunidade e/ou no povo. (LUCIANO, 2006, p. 246).

Cabe ressaltar que as comunidades indígenas têm, em geral, uma tradição oral e uma memória coletiva que dispensou por muito tempo a cultura escrita. Portanto, tratando-se de educação indígena, a escola é apenas um complemento dessa educação; logo, não é a central nem a principal. A essência da educação indígena Kaingang da Terra Indígena Linha Glória está no grupo, na família, na tradição oral, na vivência do dia a dia. É através de seu cotidiano, na convivência com os mais velhos e com os adultos, que a criança aprende por meio da tradição oral, interage e constrói significados do seu mundo cultural. Da mesma forma, há um cuidar coletivo, ou seja, todos cuidam e são responsáveis por todos. Sobre isso, o depoente H nos fala:

Esse cuidado se delega ao grupo, que vive nesta comunidade e muitas vezes, também as lideranças de outras aldeias, que vem para dar conselhos, quando necessário. Presenciei, muitas vezes, a cacique Maria Sandra saindo para uma reunião e deixando seu filho na aldeia. Falava para mim que ia tranquila, porque suas irmãs e sua mãe cuidavam dele. E aí, às vezes, as pessoas olham e tem alguns preconceitos... assim... muito fortes... no sentido de dizer que "eles são preguiçosos”. Não! Eles estão lutando para manter valores, por exemplo, estes da educação das crianças. (ENTREVISTA H, 2011, p. 4).

Com base nos estudos de Vanderléia Mussi (2000), podemos dizer que diversas populações indígenas têm salientado o propósito de que se reconheça o uso de suas tradições orais como verdadeiras histórias de vidas, uma vez que essas sociedades são tidas como ágrafas. Nesse "processo", a informação é transmitida de uma geração a outra por meio do "ouvir contar". Vanderléia Mussi, apoiando-se em Julie Cruikshank, destaca que, “[...] em termos mais gerais, a tradição oral também pode ser usada como um sistema coerente e aberto para transmitir conhecimentos." (CRUIKSHANK, 1996 apud MUSSI, 2000, p. 4).

Um dos aspectos primordiais desse grupo que perpassa a educação indígena é a aprendizagem da sobrevivência no ambiente em que vivem. Sendo assim, tomar banho em córregos, subir em árvores, pendurar-se 
em cipó constituem exercícios que se aproximam de uma educação física e talvez isso explique a dificuldade de crianças indígenas permanecerem muitas vezes sentadas em sala de aula (SILVA, 2001).

No passado, a criança indígena Kaingang aprendia, desde pequena, diferentes atividades de sobrevivência nas florestas e matas em que vivia. Eram coletores, caçadores e pescadores junto de seus pais, além de vivenciarem a prática da agricultura. Deslocavam-se sobre o território para desenvolver suas atividades de subsistência material e reprodução social. Sobre aspectos de sua educação, Ítala Becker (1995, p. 143) destaca que aos meninos era dada uma "educação prática" desde muito pequenos, sobre o uso de armas e a maneira de fabricá-las. Também enfatiza que, independentemente da faixa etária e da diferenciação de sexo, existia uma "educação prática para a vida".

Dessas atividades, tanto antes como coletores, como agora, fazendo e vendendo o balaio, as crianças sempre participaram. $\mathrm{Na}$ atualidade, eles continuam com essa prática. A criança está perto da sua mãe na hora de fazer o cesto de cipó ou de taquara e na hora de vendê-lo. Andam pelas cidades de Estrela, Lajeado, Bom Retiro do Sul, Teutônia, Montenegro. Caminham pelas ruas das cidades e também pelas estradas do interior dos municípios. Sentam no chão, por exemplo, próximos à porta do supermercado Languiru, em Teutônia. Vemos as crianças sempre junto a seus pais. Assim, aprendem o jeito de ser Kaingang. Nesse sentido, o depoente H destaca:

Na compreensão de muitos antropólogos, ela continua aprendendo a coletar como seus antepassados faziam. A organização de uma sociedade onde a mãe precisa deixar o filho na escola ou na creche e trabalhar numa fábrica o dia todo, certamente, tem necessidades, valores bastante diferentes. Estas crianças indígenas que estão na rua, estão aprendendo com seus pais, com sua vó, com a sua tia ou alguém da comunidade Kaingang. O trabalho, a vida, a aprendizagem, a busca do alimento, o respeito à natureza estão interligados. Quando leis, como a Constituição Federal vigente no Brasil ou a Convenção 169 da OIT, já consideraram e incluíram o direito de viver e ser Kaingang, cabe a todos e todas nós, respeitar as diferenças culturais e ajudar no processo de reconstrução e valorização desta sociedade brasileira plural. (ENTREVISTA H, 2011, p. 3).

Nos tempos atuais, a economia dos Kaingang modificou-se e necessitam aprender a coletar nos espaços invadidos pelas cidades. É uma lógica completamente diferente daquela vivida no passado, porém mantêm à sua maneira a especificidade da coleta. A cidade se tornou para eles uma 
extensão de seu território de "caça" e "coleta" de alimentos, remédios, documentos e outros produtos de que necessitam (TOMMASINO, 2001).

Observa-se nas Terras Indígenas, principalmente entre as pessoas mais velhas, uma ética do cuidado, no sentido de preservar o modo de vida indígena diante das possíveis mudanças, pois, mesmo considerando a dinâmica cultural, própria dos grupos humanos que se recriam diante das vicissitudes, os povos indígenas sabem o potencial destruidor do contato com as sociedades não indígenas (BERGAMASCHI; DIAS, 2009).

$\mathrm{Na}$ relação com o outro é que os grupos indígenas estabelecem justamente o que Fredrik Barth (2000, p. 26) denomina de "fronteiras étnicas". Segundo esse autor, "[...] as distinções étnicas não dependem da ausência de interação e aceitação sociais, mas, ao contrário, são frequentemente a própria base sobre a qual os sistemas sociais abrangentes são construídos.” Dessa forma, a interação não descaracteriza esses grupos sociais: "As diferenças culturais podem persistir apesar do contato interétnico e da interdependência entre as etnias.” (BARTH, 2000, p. 26). Nesse sentido, o que percebemos é que há todo um cuidado por parte dos indígenas Kaingang da Terra Indígena Linha Glória com suas "fronteiras étnicas", pois o contato com as sociedades não indígenas impulsiona para a necessidade de se afirmarem nas suas diferenças.

A educação centrada em uma instituição chamada escola é um apoio fundamental para a garantia e manutenção dessa cultura, mas, sobretudo, deve acontecer nos moldes do que prevê a lei, que garante uma educação que respeite o jeito de ser Kaingang e que seja preferencialmente trabalhada por pessoas da própria comunidade. Nesse sentido, Lylian Gonçalves (2011, p. 39) enfatiza que "[...] respeitar a cultura e o tempo das comunidades indígenas é fundamental para que se crie uma escola verdadeiramente específica e diferenciada dentro das aldeias."

\section{CONSIDERAC̣̃̃ES FINAIS}

Em se tratando de populações indígenas, ressaltamos que temos muito que aprender sobre a riqueza cultural desses povos que continuam, apesar de toda opressão sofrida durante mais de 500 anos de contato com a sociedade nacional, a manter grande parte de seus costumes antigos. Porém, é preciso considerar que, além de continuidades culturais, também 
houve transformações e, assim, foram (re)inventando novos padrões, mas sem abandonar os princípios da lógica nativa.

Constatamos, durante nossos estudos, que os Kaingang da Terra Indígena Linha Glória/Estrela mantêm viva muitas de suas tradições xamânicas e práticas de sua medicina tradicional, utilizando-se amplamente dos chás disponíveis no ambiente. Também recorrem, quando necessário, aos médicos não indígenas em questões específicas ligadas à realização de vacinas, exames pré-câncer, tratamentos dentários e problemas na coluna.

Relacionado ao problema do acesso à água, residências não dispõem de encanamentos próprios, havendo apenas uma torneira central para as cerca de 30 famílias residentes na Terra Indígena. Não há um lugar próprio para o banho, bem como não há sanitários adequados na aldeia. Como vivem em um reduzido espaço de terra e já não podem mais ter acesso aos rios como no passado, onde se banhavam frequentemente nas águas límpidas, hoje o fazem em um pequeno córrego próximo à área da aldeia, o que é extremamente precário e limitado para um grupo de praticamente 150 pessoas. Reiteramos, portanto, que é urgente a atenção com as questões de saneamento e a disponibilidade de água para as famílias Kaingang em questão.

Quanto à educação, verificamos que ela é compreendida pelos indígenas Kaingang da Terra Indígena Linha Glória como essencial à manutenção da cultura. Porém, vimos que eles entendem a educação como algo muito maior, que é dada inicialmente pelo grupo e é permeada pela tradição oral e vivências do dia a dia, em que as crianças aprendem junto a seus pais o jeito de ser Kaingang.

Durante nossa pesquisa de campo, ouvimos dos depoentes Kaingang que eles desejam que a língua materna seja revitalizada no grupo. Atualmente, não são todos que falam a língua Kaingang, porém aqueles que ainda a mantêm viva empenham-se em ensinar às crianças para que elas possam aprendê-la e, assim, dar continuidade a essa prática cultural.

A Escola Indígena Manoel Soares tem um importante papel, uma vez que deveria ser um espaço de educação indígena específica, diferenciada e bilíngue, conforme estabelecem seus direitos constitucionais garantidos pela legislação educacional brasileira. Entretanto, a partir do que pesquisamos, constatamos que a Escola Indígena Manoel Soares, que deveria ser uma 
referência nesse sentido, mesmo com o proposto da lei, não conseguiu, devido a questões adversas, manter um professor bilíngue.

A escola é tida por esse grupo como uma de suas conquistas, por isso é de fundamental importância que eles possam geri-la à sua maneira. A resolução 3/99, do Conselho Nacional de Educação (BRASIL, 1999), garante e requer a participação indígena na gestão escolar. A relação dos Kaingang da Terra Indígena Linha Glória com sua escola é o exemplo de que a educação escolar indígena pode, na atualidade, assumir um lugar de destaque para fazer valer sua luta em ver seus direitos constitucionais garantidos e que respeite, sobretudo, o direito à diferença. 


\section{REFERÊNCIAS}

ALMEIDA, L. K.; WIIK, F. B.; FERNANDES, R. C. O consumo de bebidas alcoólicas entre os Kaingang do Rio Grande do Sul. In: SILVA, G. F.; PENNA, R.; CARNEIRO, L. C. C. (Orgs.). RS Índio: cartografia sobre a produção do conhecimento. Porto Alegre: EDIPUCRS, 2009. p. 144 a 154.

BARTH, F. Os grupos étnicos e suas fronteiras. In: LASK, T. (Org.). O guru, o iniciador e outras variações antropológicas. Rio de Janeiro: Contra Capa Livraria, 2000. p. 7-67. [Original de 1969].

BECKER, Í. I. B. O indio Kaingáng no Rio Grande do Sul. São Leopoldo: Ed. UNISINOS, 1995. [Original de 1976].

BERGAMASCHI, M. A.; DIAS, F. P. Kãki karan fã: reflexões acerca da educação escolar indígena. In: SILVA, G. F.; PENNA, R.; CARNEIRO, L. C. C. (Orgs.). RS Índio: cartografia sobre a produção do conhecimento. Porto Alegre: EDIPUCRS, 2009. p. 91-103.

BRAND, A. História oral: perspectivas, questionamentos e sua aplicabilidade em culturas orais. Revista de História Unisinos, São Leopoldo, v. 4, n. 2, p. 195-226, 2000.

GONÇALVES, L. M. C. Crianças indígenas Kaingang em escola não indígena: um estudo de caso envolvendo a Escola Estadual de Ensino Fundamental Manuel Bandeira, em Lajeado/ RS. 2011. 74 f. Monografia (Especialização em Supervisão e Gestão Educacional)-Centro Universitário Univates, Lajeado, 2011.

LUCIANO, G. S. Educação Indígena. In: LUCIANO, G. S. O Índio Brasileiro: o que você precisa saber sobre os povos indígenas no Brasil. Brasília: Ministério da Educação, Secretaria de Educação Continuada, Alfabetização e Diversidade; LACED/Museu Nacional, 2006. p. $128-171$.

MATTE, D. C. Indígenas no RS: educação formal e etnicidade. In: SILVA, G. F.; PENNA, R.; CARNEIRO, L. C. C. (Orgs.). RS Índio: cartografia sobre a produção do conhecimento. Porto Alegre: EDIPUCRS, 2009. p. 104-114.

MELIÀ, B. Educação indígena e alfabetização. São Paulo: Loyola, 1979.

MORAES, C. E. N. Territorialidades indígenas e hidrelétricas. In: GOLIN, T.; BOEIRA, N. (Coords.). História - Rio Grande do Sul - Povos indígenas. Passo Fundo: Méritos, 2009. v. 5, p. 497-523.

MUSSI, V. P. L. História Oral: uma proposta metodológica em parceria com os índios ternas em Campo Grande, Mato Grosso do Sul. Campo Grande, 2000. 10 p. Datiloscrito. POSEY, D. A. Etnobiologia: Teoria e Prática. In: RIBEIRO, B. G. (Org.). SUMA - Etnológica Brasileira. Petrópolis: Finep, 1986. p. 15-25.

SILVA, A. L. Pequenos "xamãs": crianças indígenas, corporalidade e escolarização. In: SILVA, A. L.; MACEDO, A. V. L. S.; NUNES, A. (Orgs.). Crianças Indígenas, Ensaios Antropológicos. São Paulo, Global, 2001. p. 37-63.

TOMMASINO, K. Os Sentidos da Territorialização dos Kaingang nas Cidades. In: REUNIÃO DE ANTROPOLOGIA DO MERCOSUL, 4., 2001, Curitiba. Anais... Curitiba: Grupo de Trabalho Estudos Interdisciplinares Jê do Sul, 2001. 15 p. Datiloscrito. VEIGA, J. Aspectos fundamentais da cultura Kaingang. São Paulo: Curt Nimuendajú, 2006. 


\section{FONTES DOCUMENTAIS}

\section{Relatórios, ofícios e entrevistas}

BRASIL. Constituição Federal Brasileira de 1988. Brasília: Senado Federal, 1988. Disponível em: <http://www.planalto.gov.br//>. Acesso em: 20 set. 2011.

BRASIL. Ministério da Educação. Lei n. 9.394, de 20 de dezembro de 1996. Lei de Diretrizes e Bases da Educação Nacional. Diário Ofical da República Federativa do Brasil, Brasília, DF, 23 dez. 1996. Seção 1.

BRASIL. Ministério da Educação. Resolução CEB no 3/99, de 10 de novembro de 1999. Fixa Diretrizes Nacionais para o funcionamento das escolas indígenas e dá outras providências. Diário Ofical da República Federativa do Brasil, Brasília, DF, 17 nov. 1999. Seção 1. Disponível em: <http://www.portal.mec.gov.br/cne/arquivos/pdf/CEBO399.pdf>. Acesso em: 10 abr. 2012.

BRASIL. Ministério da Educação. Lei no 10172, de 09 de janeiro de 2001. Aprova o Plano Nacional de Educação. Diário Ofical da República Federativa do Brasil, Brasília, DF, 10 jan. 2001. Seção 1. Disponível em: <http://www2.camara.leg.br/legin/fed/lei/2001/ lei-10172-9-janeiro-2001-359024-publicacaooriginal-1-pl.html>. Acesso em: 10 set. 2011. BRASIL. Ministério da Educação. Decreto n ${ }^{\circ}$ 5.051, de 19 de abril de 2004. Promulga a Convenção no 169 da OIT (Organização Internacional do Trabalho) sobre os Povos Indígenas e Tribais. Diário Ofical da República Federativa do Brasil, Brasília, DF, 20 abr. 2004. Seção 1. Disponível em: <http://www.planalto.gov.br/ccivil_03/_ato2004-2006/2004/ decreto/d5051.htm>. Acesso em: 10 set. 2011.

CONSELHO ESTADUAL DE EDUCAÇÃO DO RIO GRANDE DO SUL - CEED/ RS. Parecer $n^{\circ}$ 383/2002: Estabelece normas para o funcionamento de escolas indígenas no Sistema Estadual de Ensino do Rio Grande do Sul. Lajeado: CEED/RS, 2002. Processo CEED n ${ }^{\circ}$ 429/27.00/02.7.

ESCOLA ESTADUAL INDÍGENA DE ENSINO FUNDAMENTAL MANOEL SOARES. Relação de alunos matriculados na Escola Estadual Indígena de Ensino Fundamental Manoel Soares da aldeia Linha Glória. Estrela: MelhorEscola.NET, 2011. 1 p.

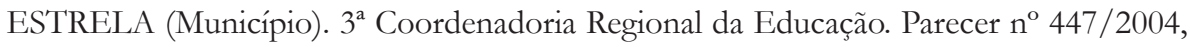
em 7 de julho de 2004. Ofício da AJU/GAB/3a CRE no 849, de 25 de agosto de 2004. Sobre Autorização de funcionamento da Escola Estadual Indígena de Ensino Fundamental Manoel Soares. Diário Oficial do Estado do Rio Grande do Sul, Porto Alegre, jul. 2004.

ENTREVISTA A - EA. Depoente A. Realizada em 23 de fevereiro de 2011. Estrela: [s.n.], 2011. Gravação em máquina digital 6.0 Mega Pixels. Duração 55min 30s. Transcrito. ENTREVISTA B - EB. Depoente B. Realizada em 15 de março de 2011. Lajeado: [s.n.], 2011. Gravação em máquina digital 6.0 Mega Pixels. Duração 27min 48s. Transcrito.

ENTREVISTA D - ED. Depoente D. Realizada em 22 de março de 2011. Estrela: [s.n.], 2011. Gravação em máquina digital 6.0 Mega Pixels. Duração 24min 50s. Transcrito.

ENTREVISTA E - EE. Depoente E. Realizada em 22 de março de 2011. Estrela: [s.n.], 2011. Gravação em máquina digital 6.0 Mega Pixels. Duração 16min 58s. Transcrito. 
ENTREVISTA H - EH. Depoente H. Realizada em 06 de maio de 2011. Lajeado: [s.n.], 2011. Gravação em máquina digital 6.0 Mega Pixels. Duração 31 min 47s. Transcrito.

FUNDAÇÃO NACIONAL DA SAÚDE - FUNASA. Ofício nº 119 SENSP/FUNASA/ CORE-RS, de 15 de fevereiro de 2007. Lajeado: Ministério Público Federal, 2007. Resposta ao Procedimento Administrativo - PA no 1.29.014.000009/2007-72.

GONÇALVES, J. R. Relatório Final Antropologia na área de duplicação da BR-386, Triunfo, Tabai, Taquari, Fazenda Vila Nova, Bom Retiro do Sul e Estrela - RS Aldeia Kaingang TI Estrela. Tubarão: Universidade do Sul de Santa Catarina, 2008.

LAJEADO (Município). Procuradoria da República da 4. ${ }^{2}$ região. Procedimento Administrativo - PA n ${ }^{\circ}$ 1.29.014.000060/2004-31, de 10 de agosto de 2004. Lajeado: [s.n.], 2004a.

LAJEADO (Município). Procuradoria da República no Município - PRM. Procedimento Administrativo - PA n 1.29.014.000008/2003-02, de 19 de maio de 2004. Lajeado: [s.n.], 2004b.

LAJEADO (Município). Procuradoria da República no Município - PRM. Relatório da $3^{\text {a }}$ Coordenadoria Regional de Educação. Relatório de 26 de agosto de 2004. Sobre a situação inicial da Escola Estadual Indígena de Ensino Fundamental Manoel Soares. Lajeado: PRM, 2004c.

RIO GRANDE DO SUL. Secretaria da Educação do Estado do Rio Grande do Sul. Decreto n ${ }^{\circ}$ 41.700, de 03 de julho de 2002. Diário Oficial do Estado do Rio Grande do Sul, Porto Alegre, 04 jul. 2002.

\section{NOTAS}

1 Para se tornar um Kuiã, que pode ser homem ou mulher, [...] a pessoa deve ser iniciada por um Kuiã mais velho, que vai mostrar para ela quais os remédios com os quais ela vai se lavar e tomar para receber seu iangrẽ. Esse remédio deve ser usado durante nove dias. Cumprida essa prescrição o iangrẽ vem ao encontro da pessoa [iangrẽ pode ser qualquer bichinho do mato: tigre, coruja, gavião... O Kuiã fala com o iangrẽ e juntos vão buscar as coisas: ervas, almas...]. A pessoa que tem um iangrẽ deve evitar matar animais daquela espécie. (VEIGA, 2006, p. 172, grifo do autor).

2 Entre os muitos vegetais utilizáveis pelos Kaingang, destacamos ainda a palmeira e a taquara. Sobre isto Ítala Basile Becker (1995, p. 176) informa que a taquara "[...] é uma planta de referência na vida dos Kaingang; dela se valem para a contagem do tempo, pois uma taquara ou período que vai de uma floração a outra da planta, corresponde a 30 anos." Dentre as demais utilidades deste vegetal, a autora ressalta o uso "[...] para cortar o cabelo, para suas flechas, bem como para o fabrico de cestos, chapéus e ventarolas que confeccionam com grande habilidade para fins domésticos, comerciais e também para instrumentos de música."

3 É importante esclarecer, segundo Becker (1995), que somente a partir do século XIX identifica-se, entre os Kaingang, toda uma relação de direitos e deveres para a primeira 
infância (período que vai do nascimento até os 11 ou 12 anos para os meninos, e até os 14 ou 15 anos, para as meninas); a adolescência (para os rapazes vai dos 12 até por volta dos 20 e 24 anos); passado isto, já é a fase adulta. As meninas, após a primeira menstruação, vão diretamente para a fase adulta. Atingida a idade de 14 ou 15 anos e já tendo menstruado, devem atender às necessidades que lhes der a liderança Kaingang. Por meio do casamento, entram ambos os sexos para a idade adulta.

Recebido: 23/05/2012

Aprovado: 06/05/2013

Contato:

Unidade Integrada Vale do Taquari de Ensino Superior Pós-graduação em Ambiente e Desenvolvimento Rua Avelino Tallini, 171, Bairro Universitário CEP 95900-000 Lajeado, RS Brasil 